\title{
Desenvolvimento da pesquisa em Contabilidade Gerencial: as restrições da abordagem monoparadigmática de Zimmerman
}

\section{Management accounting research development: the restrictions of Zimmerman's monoparadigm approach}

\author{
Fábio Frezatti ${ }^{1}$ \\ Professor Livre-Docente do Departamento de Contabilidade e Atuária da Faculdade de Economia, Administração e Contabilidade da \\ Universidade de São Paulo • E-mail: frezatti@usp.br
}

Artur Roberto do Nascimento

Doutorando do Programa de Pós-graduação em Ciências Contábeis da Faculdade de Economia, Administração e Contabilidade da

Universidade de São Paulo e Professor Assistente do Departamento de Ciências Sociais Aplicadas da Universidade Estadual de Feira de Santana

- E-mail: artnascimento@usp.br

Emanuel Junqueira

Doutorando do Programa de Pós-graduação em Ciências Contábeis da Faculdade de Economia, Administração e Contabilidade da Universidade de São Paulo e Professor Assistente do Departamento de Ciências Contábeis do Centro de Ciências Jurídicas e Econômicas da

Universidade Federal do Espírito Santo • E-mail: ejunqueira@usp.br

Recebido em 09.05.2008 • Aceito em 25.09.2008 $\cdot 2^{a}$ versão aceita em 16.10.2008

\section{RESUMO}

Este trabalho tem por objetivo analisar o desenvolvimento conceitual da Contabilidade Gerencial levando em conta suas peculiaridades e influências possíveis. Trata-se de um ensaio baseado em uma pesquisa bibliográfica que identificou demandas, conflitos e necessidades metodológicas para a pesquisa em Contabilidade Gerencial, tendo como pano de fundo um debate entre Ittner e Larcker (2001; 2002), Zimmerman (2001), Hopwood (2002), Lukka e Mouritsen (2002) e Luft e Shields (2002), considerados extremamente destacados na análise dos rumos da pesquisa em Contabilidade Gerencial. A justificativa para o estudo está na percepção de que o desenvolvimento das ciências depende, além de estudos que buscam seu crescimento linear, de estudos que se dediquem à reflexão crítica sobre o conhecimento nelas produzido. A inovação consiste na discussão das especificidades da área, a apresentação do monoparadigma como limitador de pesquisa, as teorias organizacionais como oportunidades, o poder político do mainstream e a falta de rigor metodológico dos trabalhos. Conclui que o crescimento da Contabilidade Gerencial decorre de inúmeros elementos, fundamentais para o crescimento qualitativo das pesquisas na área, destacando-se a necessidade de uma clara personalidade para as pesquisas, a não aceitação do monoparadigma e um maior compromisso dos pesquisadores no que se refere à profundidade metodológica.

Palavras-chave: Teoria da Contabilidade Gerencial. Contabilidade Gerencial. Monoparadigma Econômico.

\section{ABSTRACT}

This study aims to analyze the conceptual development of management accounting, in view of its peculiarities and possible influences. This is an essay based on a bibliographic research. The goal is to identify demands, conflicts and methodological needs for management accounting research, against the background of a debate between Ittner and Larcker (2001; 2002), Zimmerman (2001), Hopwood (2002), Lukka and Mouritsen (2002)

10 autor agradece ao apoio do CNPq e FAPESP. 
and Luft and Shields (2002), who are considered extremely relevant in analyzing the course of management accounting research. The innovation consists in discussing research particularities, the monoparadigm as a limiting factor of research, organizational theories as research opportunities, the political power of mainstream and the lack of methodological rigor in the studies. It is concluded that the growth of management accounting derives from countless elements, fundamental for the qualitative improvement of research. Among them, the need for a clear personality for research, the non-acceptance of the monoparadigm and the researchers' greater responsibility in terms of methodological depth are highlighted.

Keywords: Management control. Management accounting. Economic monoparadigm.

\section{INTRODUÇÃO}

Ittner e Larcker (2001) despertaram a ira de Zimmerman (2001) quando tentaram apresentar uma análise sobre o fracasso da Contabilidade Gerencial em desenvolver trabalhos empíricos que produzissem conhecimentos crescentes para a área. Eles inseriram o tema em um trabalho destinado a entender o estado da arte da pesquisa empírica em Contabilidade Gerencial, a partir do arcabouço normativo denominado gestão de valor, utilizando-se de referências frágeis na sua estruturação, principalmente porque o arcabouço de gestão baseada em valor foi fornecido por empresas de consultoria. Fizeram o que não deviam na pesquisa: uma parte relevante dos dados usados na fundamentação do trabalho estava ligada a "achismos" não comprovados empiricamente. Tal trabalho foi publicado em um periódico extremamente valorizado pelos positivistas, o Journal of Accounting and Economics (JAE), em uma edição especial destinada a efetuar uma revisão de literatura do estado da arte da pesquisa contábil. No mesmo periódico, Zimmerman publicou uma crítica dura e desconcertante. Se numa análise global essas críticas faziam algum sentido, com a apresentação de elementos de advertência importantes para a reflexão, em alguns momentos o autor leva para o lado pessoal, distanciando-se de uma discussão científica, que realmente contribuiria para a evolução do debate. O ponto central de suas críticas era o afastamento do monoparadigma econômico apresentado pelo trabalho de Ittner e Larcker (2001).
Zimmerman (2001) criticou o estágio da produção científica da Contabilidade Gerencial que tem se acomodado com estudos de casos em que não existe demonstração de chances de se tornar uma teoria generalizada, bem como valorização do que chamou de literatura de "práticos" que não estariam proporcionando base sólida para o crescimento do conhecimento. Adicionalmente, a análise desse debate, também, revela como o mundo da pesquisa envolve a manipulação e o poder do mainstream.

Hopwood (2002), Lukka e Mouritsen (2002), Luft e Shields (2002) e os próprios causadores do destempero de Zimmerman (ITTNER; LARCKER, 2002) publicaram artigos em diferentes veículos tratando individualmente alguns pontos de concordância e de discordância que ainda são atuais no mundo da pesquisa com aprendizados relevantes.

Não se trata de uma discussão entre anglosaxões, sobre algo em que os latinos nada teriam a contribuir. Pelo contrário, os trabalhos devem provocar uma profunda reflexão sobre o que ocorre em termos de desenvolvimento na Contabilidade Gerencial no Brasil. Essa reflexão permitiria o entendimento de alguns problemas existentes e limitações percebidas. Afinal, os tempos de crescente globalização exigem que os pesquisadores estejam muito atentos ao desenvolvimento dos demais centros, não apenas acompanhando contemplativamente, mas trazendo contribuições. Nesse sentido, este trabalho pretende identificar, sob a forma de um ensaio teórico, os aspectos 
mais importantes do debate e particularizálos no que se refere às especificidades do ambiente nacional.

Para tratar essas questões, foi desenvolvida análise em que os seis artigos representam "o pano de fundo" para a discussão realizada sob a diretriz da seguinte questão: o monoparadigma econômico é suficiente para atender questões de pesquisa pertinentes às necessidades da Contabilidade Gerencial?

Muito longe de pretender uma resposta dicotômica, a questão de pesquisa pretende provocar uma reflexão no leitor, pois, ao responder a essa reflexão, espera-se um posicionamento com consequências práticas no desenvolvimento da carreira do pesquisador por meio do "como" fazer. O trabalho caracteriza-se como um ensaio, pois desenvolve uma proposta a respeito de um determinado tema a partir da análise de trabalhos desenvolvidos sobre Contabilidade Gerencial (SANTOS, 1999). No caso deste trabalho, refere-se a uma avaliação dos aspectos epistemológicos da Contabilidade Gerencial, particularmente, no que tange à validade do monoparadigma econômico proposto por Zimmerman (2001) para suas pesquisas.

Para Kuhn (1970), "paradigmas [são] as realizações científicas universalmente reconhecidas que, durante algum tempo, fornecem problemas e soluções modelares a uma comunidade de praticantes de uma ciência". O presente trabalho inspira-se nesta noção de paradigma para descrever uma concepção de monoparadigma econômico que corresponde a utilização exclusiva da teoria econômica, particularmente a teoria neoclássica e seus aperfeiçoamentos, para a explicação dos fenômenos contábeis. Nesse caso, a teoria econômica seria a base predominante utilizada pela "comunidade de pesquisadores contábeis" para a explicação de todas as questões relacionadas ao seu objeto de estudo.

Em oposição a um monoparadigma econômico e inspirado nos estudos de Burrel e Morgan (1977), o trabalho apresenta a noção de pesquisa multiparadigmática que considera que a miríade de problemas encontrados na pesquisa em Contabilidade Gerencial demanda uma multiplicidade de enfoques e visões para o entendimento da plenitude de seu objeto de estudo. Essas visões podem ser apoiadas na teoria econômica, como defendida pelos ortodoxos, tal como preconizado por Zimmerman, como por outras teorias sociais como a psicologia.

Para atender a questão de pesquisa, o artigo apresenta, além dessa introdução: (i) uma exposição dos principais pontos dos seis trabalhos; (ii) uma exposição do referencial teórico que está por trás da visão de Zimmerman; (iii) a análise dos principais pontos levantados e (iv) comentários finais com recomendações para os pesquisadores de Contabilidade Gerencial.

\section{ANÁLISE DOS ARTIGOS QUE ESTIMULARAM A DISCUSSÃO}

O debate apresentado no início deste artigo foi constituído por uma pesquisa empírica e cinco ensaios, que são analisados em sua sequência de publicação.

\subsection{Ittner e Larcker (2001)}

Os autores fazem uma análise do estado da arte da pesquisa empírica em Contabilidade Gerencial, discutindo questões teóricas e metodológicas, a partir do arcabouço do que denominaram gestão baseada em valor, que inclui, dentre outros, os artefatos $\mathrm{ABC}$ - Custeio Baseado em Atividades, Balanced Scorecard (BSC), Contabilidade Estratégica e sistema de controle e medidas econômicas de mensuração. Basicamente, desenvolve uma revisão de literatura dos trabalhos empíricos em Contabilidade Gerencial, fundamentados em metodologia de survey ou arquivo, no nível organizacional. Foram excluídos tra- 
balhos de Contabilidade Comportamental, casos, experimentos e estudos de remuneração. Ao escolher a gestão baseada em valor, ficaram cativos em termos de fontes literárias entendidas pelo mainstream como sendo menos acadêmicas e entidades que se dedicam a consultorias (citam McKinsey, PWC e KPMG, por exemplo). Do ponto de vista de plataforma teórica, a teoria da agência, o modelo econômico de arquitetura organizacional e teorias da contingência proporcionam o construto utilizado para o desenvolvimento do trabalho.

Os autores (2001, p. 355-358) abrem a discussão sobre insatisfações quanto ao estágio da Contabilidade Gerencial no meio do desenvolvimento do artigo. Entendem que os temas tratados na Contabilidade Gerencial, predominantemente, são os importantes (hot) para o momento vivido, principalmente os que consideram derivados de mudanças nas práticas. Por um lado reconhecem que esse tipo de abordagem aproxima a pesquisa dos práticos, ou seja, aqueles considerados "não puramente acadêmicos". Os autores reconhecem que o fato de sua revisão se voltar para tendências emergentes de Contabilidade Gerencial leva a incluir tópicos que têm recebido muita atenção da mídia de negócios. Por outro lado, esse enfoque demanda pesquisa de material construído de maneira não necessariamente rigorosa em termos de um arcabouço teórico e com baixa teorização.

Mencionam, também, o fato de que a generalização de conhecimentos no sentido de criar e sedimentar abordagens teóricas mais consistentes não tem ocorrido com frequência. Consideram que as causas, dentre várias, são: (i) muitos tópicos não são amadurecidos criticamente e aprofundados ao longo do tempo, gerando lacunas teóricas não resolvidas e com falta de sequência dos estudos; (ii) diferenças nas abordagens, dada a utilização de uma grande diversidade de fontes conceituais, oriundas não apenas da economia, mas também da psicologia, sociologia etc.
Isso ocorre, principalmente, fora dos Estados Unidos já que a formação Americana foca mais a abordagem econômica; (iii) baixa condição de publicação dos trabalhos da Contabilidade Gerencial. Nesse ponto, mencionam a dificuldade de obter dados, em comparação com a Contabilidade Financeira que se utiliza de dados públicos padronizados disponíveis nos órgãos reguladores do mercado e bancos de dados comerciais, a Contabilidade Gerencial tem que produzir seus achados principalmente a partir de survey, o que encarece e dificulta as pesquisas. Já que a disponibilidade de dados publicados referentes à Contabilidade Gerencial é diferente e, por serem raros os dados, são obtidos por meio de amostras tão heterogêneas. Essa heterogeneidade torna a comparabilidade restrita e limitada, bem como a generalização mais difícil. Adicionalmente, esse problema pode levar o pesquisador a escolher o tema de pesquisa em função da disponibilidade de dados.

\subsection{Zimmerman (2001)}

As críticas de Zimmerman iniciam-se pela conclusão de que a literatura em Contabilidade Gerencial tem falhado em produzir conjunto substantivo de conhecimento. A partir desse ponto passa a analisar o artigo de Ittner e Larcker (2001) como referência para seus argumentos. $\mathrm{O}$ autor critica o estado atual da pesquisa em Contabilidade Gerencial, discutindo por que há poucas generalizações teóricas dos achados das pesquisas e por que o trabalho de Ittner e Larcker (2001) cita pequena quantidade de artigos do mainstream norte-americano. Considera que o trabalho dos citados autores foi fundamentado em trabalhos de "práticos" e periódicos não norteamericanos, ou seja, fora do mainstream contábil considerado por Zimmerman. Em sua opinião, o grande foco da pesquisa contábil gerencial concentra-se apenas em descrever os fenômenos observados, ao invés de gerar teorias para a predição de eventos (uma teoria positiva). De forma mais específica, suas 
principais colocações sobre o artigo de Ittner e Larcker (2001) são as seguintes:

- A busca pelo embasamento conceitual do tema gestão de valor foi direcionado para trabalhos da McKinsey (COPELAND et al., 1996) e KPMG, com visão normativa exclusivamente e nada apresentando em termos de teoria positiva, no sentido de explicar como predizer fenômenos. Dessa forma, a Contabilidade Gerencial só estaria descrevendo e não gerando e testando teorias. $\mathrm{Na}$ verdade, considera que a pesquisa descritiva sozinha estaria voltada para oportunidades de consultoria;

- Ao analisar, qualitativamente, a literatura, entende que as citações, mesmo que frequentes, não devem ser dúbias e devem retratar um dado rigor metodológico para que inferências sejam plausíveis. Para se posicionar, fez uma comparação do artigo tratado com os demais oito artigos de revisão de literatura do mesmo exemplar do JAE. Nesse sentido, os autores (ITTNER; LARCKER, 2001) citam pouco o mainstream norte-americano (23\%) e citam mais predominantemente a literatura dos "práticos" e dos outros periódicos como, por exemplo, o Accounting, Organization and Society (AOS), o Journal of Management Accounting Research (JMAR), o Management Accounting Research (MAR), o Accounting Horizons $(A H)$, dentre outros. Entende que isso decorre tanto dos objetivos amplos dos autores como da pequena publicação nos periódicos norte-americanos. Considera "dramática" a baixa quantidade de citações de fontes com perspectivas econômicas, de finanças e literatura estatística em comparação com os demais artigos do exemplar do periódico em que o artigo de Ittner e Larcker (2001) se insere. Traduz sua crítica mostrando que as citações (ao menos quantitativamente) também não se enquadram em outras áreas do conhecimento que justifiquem a fuga ao construto de economia e finanças;

- Enfatiza a importância do papel da teoria na pesquisa e considera que um dos motivos da falha em Contabilidade Gerencial em produzir "corpo coerente de conhecimentos" decorre do fato de não adotar o objetivo de testar teorias. Nos poucos casos em que isso ocorre, elas derivam de uma variedade de diferentes disciplinas. Considera que nenhuma teoria unificada baseada em economia foi construída para guiar a pesquisa em Contabilidade Gerencial e que essa teoria permite a acumulação sistemática do conhecimento. Por sua vez, a construção teórica e a pesquisa empírica interagem. Ao testar as hipóteses derivadas de teoria, pode-se acumular conhecimento no sentido de que hipóteses refutadas provocam revisões de teorias para entendimento dos fenômenos investigados. Cita Hempel (1966, p. 13) que alerta que, sem hipóteses, a análise de dados é cega. Ainda que entenda que as teorias não devam ser apresentadas apenas em termos matemáticos, mas sim por meio da lógica de análise, a matemática torna a lógica mais rigorosa e transparente.

- Oferece seis explicações para o fracasso da literatura empírica da Contabilidade em acumular conhecimento sistemático: (i) ausência de dados, ele entende que o "mantra" da falta de dados não pode ser justificativa para a ausência de pesquisa e pobreza da área. Segundo ele, falta criatividade aos pesquisadores. Cita exemplo de Lazear (2000, p. 420) de que, em áreas não tradicionais da economia, os pesquisadores têm utilizado métodos criativos para a execução dos trabalhos, sendo que discute as causas e menciona que os periódicos 
do mainstream publicaram 24 estudos empíricos em Contabilidade Gerencial, entretanto não esclarece em que horizonte de tempo, com o argumento de que eles também publicam tais trabalhos; (ii) a abordagem indutiva não guiada por uma teoria, enfatizada por Harvard, que se preocupa em entender e documentar as práticas gerenciais das empresas. Cita os trabalhos de Kaplan em 1983, 1984 e 1986, o trabalho de Bruns e Kaplan de 1987 e o trabalho de Hopwood de 1983 como estimuladores desse tipo de iniciativa, numa abordagem indutiva ao invés de proposta dedutiva. Menciona que muito tempo já decorreu desde os primeiros trabalhos, nos quais se alegava ausência de teoria para avançar e, portanto, essa não seria uma justificativa plausível; (iii) incentivos para pesquisa, que considera que foram alterados para o foco em consultorias, que são valorizadas pelos alunos das instituições de ensino muito mais do que as teorias; (iv) sustentação conceitual não econômica. Nesse sentido, cita Lazear (2000) que argumenta: "economics is the premier social science". Atribui o sucesso da economia por ser uma "ciência maior" e muito do conhecimento contábil advém dela. Indica que todas as áreas revisadas nesta edição especial do JAE (accounting choice, teoria da agência em Contabilidade, Governança Corporativa, disclosure, impostos e value-relevance) utilizaram como arcabouço teórico a economia. Menciona, também, que outras áreas das ciências sociais aplicadas, tal como a psicologia cognitiva, podem trazer contribuições para a Contabilidade, entretanto enfatiza que a fertilidade das teorias decorrentes da economia sobrepujam as demais áreas; além disso, a utilização de uma miríade de abordagens teóricas gera uma per- da de economia de escala; (v) poucas teorias passíveis de serem testadas no sentido de previsões. Os trabalhos realizados pelos teóricos em Contabilidade Gerencial não apresentam análise sobre suas implicações empíricas (hipóteses) para serem tratados pelos pesquisadores, isso gera uma lacuna de pesquisa entre os trabalhos realizados por mais de um pesquisador. $\mathrm{Na}$ verdade, o questionamento desse item é a frequente ausência da abordagem preditiva sendo aplicada; e (vi) ênfase na decisão e não no controle, já que o sistema contábil serve tanto para a tomada de decisão como para controle. Zimmerman afirma que o controle tem um papel relevante de reduzir conflitos de agência e entende que, no equilíbrio econômico, as pesquisas parecem propor que os sistemas contábeis não são usados para controle. Menciona, ainda, que o termo "contador" tem uma conotação negativa entre estudantes e "práticos", sendo o motivo para que o enfoque decisorial fosse privilegiado em detrimento das pesquisas relacionadas ao controle.

\subsection{Hopwood (2002)}

O editor emérito do periódico AOS inicia sua crítica entendendo que os comentários de Zimmerman, levando em conta a razão e a emoção, revelariam perspectivas subjacentes e preconceitos que existem na atividade acadêmica. Nesse sentido, a fascinação que o mainstream exerce sobre a comunidade acadêmica, a preocupação com a América do Norte, deixando de reconhecer contribuições dos australianos, escandinavos e indianos, dentre outros, e a glorificação do status e potencial da economia está por trás de toda a análise de Zimmerman. Isso ocorre desde o início, quando ignoram as origens da gestão de valor e também da ausência de referências não norte-americanas sobre cus- 
tos e mensuração de desempenho, dentre outros. Hopwood não quer que se entenda que as críticas ao trabalho de Ittner e Larcker sejam injustificadas. Pelo contrário, percebe que as opções das fontes de pesquisas feitas pelos autores pendem para uma abordagem de consultoria no lugar do que chamou de "sabedoria de pesquisa e experiência". Dessa maneira, entende que Zimmerman foi até generoso demais. Os pontos relevantes do seu comentário são os seguintes.

Sobre o mainstream, Hopwood menciona que Zimmerman considera como tal apenas alguns periódicos, excluindo outros, demonstrando uma forte abordagem normativa na definição do que seria o mainstream, sugerindo que a boa pesquisa teria de ser lá publicada. Nesse ponto argumenta que publicar nesses periódicos, além de condição de avaliação, passa também por uma dimensão de poder exercido pelo sistema acadêmico norteamericano, orientado pelo modelo de carreira acadêmica vigente no país. Dessa maneira, o sistema de publicação funciona dentro dos paradigmas estabelecidos pelos periódicos, o que torna a inovação um risco quando o construto teórico e metodológico fugir do mainstream estabelecido. No nível individual, demonstra preocupação com o que chama de necessidade do autor de citar os editores e os potenciais revisores daqueles periódicos aos quais submetem trabalhos. Cita em especial o The Accounting Review, cujos aspectos políticos na nomeação dos editores faz com que a "isenção editorial" seja reduzida. Se, por um lado, reconhece que as características desses periódicos também contribuem para a acumulação do conhecimento e entende que alcançaram a posição no passado por terem sido questionadores e inovadores, por outro lado, hoje, se tornaram conservadores. Cita como argumento para isso o então presidente da American Accounting Association, Joel Demski (2002) que recomendou aos pesquisadores, de acordo com Hopwood (2002, p. 777), "[...] to focus on topic, without reference to method, section or interest group 's so as increase trade amount our various specialities and put accounting per se back in the center of four scholarly activities." Adicionalmente cita Dye (2001, p. 230-231), importante pesquisador da área de disclosure, na mesma edição do periódico, que critica a própria pesquisa em Contabilidade Financeira em relação ao estágio de publicações (por ser mais computacional do que conceitual), a falta de estudo dos "grandes" problemas e a avançada idade dos pesquisadores, o que os torna conservadores, mais reacionários, defensores das produções passadas.

Depois de discutir aquilo que considera relevante, Hopwood faz o contraponto, mencionando que Zimmerman teceu vários comentários "sábios e úteis". Embora, ao final da sua apreciação, Hopwood tenha reconhecido a relevância do conhecimento econômico na pesquisa e interesse crescente dos pesquisadores, sua abordagem foi de confronto perante Zimmerman. Um dos pontos mencionados diz respeito aos dados utilizados por Ittner e Larcker, já que a Contabilidade Gerencial nem é algo unitário nem homogêneo, na prática, consiste em um conjunto de diferentes práticas e técnicas "vagamente ligadas" e de diferentes maneiras em diferentes organizações, apesar da tendência de grande integração. Isso torna a pesquisa mais difícil. Caracterizar essas dificuldades como "dados pobres" pela visão carreirista do mainstream no lugar de entendê-las como desafios de pesquisa deixa de trazer motivação para uma genuína curiosidade intelectual. As áreas de organizações e sociologia aplicadas à Contabilidade Gerencial têm articulado questionamentos quanto às pesquisas com ausência de base teórica, ou mesmo desenvolvimento de pesquisa aplicada com a ausência de uma problemática amadurecida, mostrando que, embora Zimmerman tenha questionado tal ponto exclusivamente focando como solução o monoparadigma, o problema por ele tocado realmente existe. Entende que essa ques- 
tão tem profundo impacto sobre o processo de pesquisa em Contabilidade Gerencial, pois pode incentivar a superficialidade no lugar de uma busca substantiva e um trabalho "da moda" no lugar de algo mais duradouro. Se, nesse ponto, Hopwood concorda com Zimmerman sobre a inadequação pela abordagem "da moda", por outro discorda que a análise apresentada dá sustentação para a discussão sobre o último tema.

Por fim, é importante lembrar que o periódico AOS, do qual Hopwood é o editor, vem se destacando por publicar pesquisas com múltiplas abordagens teóricas, desvinculadas do mainstream do monoparadigma norteamericano, defendido por Zimmerman, e, portanto, qualificado para tecer críticas aos seus comentários.

\subsection{Lukka e Mouritsen (2002)}

Os dois autores dedicaram-se a discutir, basicamente, a questão do que chamaram de paradigma monolítico baseado na teoria econômica. Entendem que a visão econômica oferece uma abordagem estreita do mundo e cria uma área de aspectos "não discutíveis" por estarem fora do paradigma econômico e serem provenientes da abordagem de Kuhn (1970), que prescreve a "ciência normal", a partir de um único paradigma. Essa visão, na opinião de Lukka e Mouritsen (2002), limita as posições críticas e ameaça a habilidade da Contabilidade Gerencial. Dessa maneira, advogam o contrário de Zimmerman, ou seja, a heterogeneidade nas pesquisas em Contabilidade Gerencial.

Os autores discutem cinco aspectos da crítica de Zimmerman (2001): (i) a preocupação é legítima e importante, ou seja, como pode ser criada boa pesquisa em Contabilidade Gerencial? Não têm nenhuma dúvida de que o rigor é relevante. Concordam que deva existir mais rigor, mais testes e mais teoria. Entendem a teoria "[...] como sendo a tentativa do nosso mundo de fazer sentido num nível mais abstrato do que simplesmen- te descrever a realidade imediata percebida." (LUKKA; MOURITSEN, 2002, p. 806). Os testes deveriam ser vistos como tentativa de busca pelas conexões que contenham o mundo. Nos paradigmas da Contabilidade Gerencial, o pesquisador tem liberdade; quanto mais limitados forem, menos espaços terão para trabalhar o rigor, o teste e a teorização. Nesse sentido, defendem Ittner e Larcker por terem utilizado, basicamente, dados de pesquisas documentais e empíricas exatamente para que pudessem ser testadas. Finalmente, embora tenham utilizado o mainstream norte-americano e o paradigma econômico, ele não é a única voz possível, o que pode ser percebido pela visão global da Contabilidade Gerencial, que pede pluralismo; (ii) homogeneidade versus heterogeneidade em pesquisa. Para os autores, o monoparadigma confina os pesquisadores no lugar de libertálos. Na verdade, a adoção do patrocínio de um único paradigma nada tem de científico. Mesmo que o paradigma econômico tenha muito a oferecer, pressionar a Contabilidade Gerencial a ter apenas um paradigma gera o problema de ter temas "não passíveis de discussão”, já que, na visão do positivismo econômico de Zimmerman, alguns problemas não teriam relevância e, consequentemente, nem deveriam ser pesquisados. O grande benefício da "ciência normal" de Kuhn é produzir conhecimento eficientemente. Isso é possível desde que o pesquisador disponha de premissas fundamentais e disponibilidade de metodologia adequada. Ao mesmo tempo em que a eficiência da "ciência normal" pode ser atraente e confortadora, pode ser perigosa e decepcionante, pois ignora que as observações não falam por si mesmas, mas podem ser tratadas por diferentes paradigmas. Citam vários autores (MILLER, 1998; AMSTRONG, 1985; WALLANDER, 1999) que questionaram aspectos relevantes não tratados pelo paradigma econômico. Ao final, propõem que os pesquisadores não se atenham apenas ao "SE" a Contabilidade Gerencial funciona, 
mas sim "COMO" funciona, mesmo que seja em um tipo de situação limitada; (iii) como generalizar. A generalização pretendida por Zimmerman tem um papel relevante tanto na Contabilidade Gerencial baseada nos fundamentos econômicos como nas outras áreas. Na verdade, a acumulação do conhecimento ocorre quando os pesquisadores adicionam novas proposições "falseáveis", no sentido Popperiano. A generalização é diferente na Contabilidade Gerencial, já que os estudos empíricos são comparados com situações descritas e analisadas em estudos anteriores, o que significa que os resultados dos estudos individuais são generalizáveis quando, comparandoos aos achados de outros estudos, for possível relacioná-los. Por outro lado, reconhecem que não tem sido muito efetivo na geração de respostas para o "SE"; (iv) diferentes agendas de pesquisa e diferentes histórias. Consideram que, ao responder a questão "SE", a pesquisa típica de paradigma econômico pode proporcionar respostas que sejam difíceis de serem entendidas. Ao responder o "COMO" é possível entender a sequência de elementos que devam existir para tornar a Contabilidade Gerencial interessante. Mostram que um mesmo fenômeno pode ser tratado sob diferentes abordagens e perspectivas. Nesse caso, sendo distintos, exigem diferentes teorias e, ao cair no monoparadigma, tais abordagens não serão consideradas e a pesquisa se tornaria mais pobre e $(\mathrm{v})$ pela heterogeneidade. Como conclusão, propõem que o ambiente é heterogêneo e, como consequência, o paradigma da pesquisa também deveria sê-lo. Consideram "interessante" notar que a demanda para a pesquisa "normal" seria uma tentativa de estabelecimento de normas para seu funcionamento.

\subsection{Luft e Shields (2002)}

Esses autores apresentam os seguintes argumentos: (i) teoria versus descrição das práticas - a colocação de Zimmerman não está adequada. Citam, como evidência disso, o trabalho de Luft e Shields (2003) que revisa a utilização de teorias na pesquisa em Contabilidade. Eles asseveram que, algumas vezes, na pesquisa em Contabilidade Gerencial, pode ocorrer uma utilização incompleta ou inapropriada da teoria, mas não a inexistência dela; (ii) decision-making versus controle - tal como descrito pelos próprios autores, a revisão efetuada por Ittner e Larcker desconsiderou muito trabalhos que têm um foco em controle, como, por exemplo, os estudos baseados em experimento e alguns estudos de compensação. Nesse sentido, não é possível afirmar que a literatura enfatiza os estudos com foco em decisão. Adicionalmente, indica que a comunidade não decidiu que o papel de controle é mais importante que o de decisão. Citam Demski et al. (2002, p. 161), que asseveram que o centro da disciplina de Contabilidade assenta-se em uma tensão multidimensional entre tomada de decisão e controle e que a resolução dessa tensão não é simples; (iii) economia versus outras ciências sociais - a Contabilidade Gerencial tem utilizado teorias provenientes de diversas áreas para o entendimento de seus fenômenos (precipuamente economia, psicologia e sociologia) e que a ciência econômica não pode responder aos diversos problemas existentes na Contabilidade Gerencial. Além disso, como toda ciência social, a economia possui limitações (diferentes distribuições de erros). Por exemplo, o entendimento geral do comportamento humano tem sido buscado em outras ciências sociais fora do "mainstream" econômico. Citando Baiman (1990), indicam que muitas das teorias da economia não são baseadas em modelos formais rigorosos e exemplificam a pesquisa em agência da Rochester School que se baseou em argumentos intuitivos utilizando-se de terminologias econômicas. Ademais, outras áreas como psicologia e sociologia têm oferecido teorias com rigorosos modelos matemáticos. Citam a pesquisa em redes neurais de trabalho da psicologia cognitiva e a dinâmica organi- 
zacional da população em sociologia como exemplos.

Evidenciam que as premissas de racionalização e equilíbrio presentes na ciência econômica não satisfazem, adequadamente, a muitas questões de pesquisa em Contabilidade Gerencial. Advogam, também, que a utilização de uma teoria deve ser justificada pela necessidade da questão a ser estudada e não apenas pela identidade que o pesquisador possui com a disciplina.

\subsection{Ittner e Larcker (2002)}

Nesse artigo, o trabalho que originou o debate (ITTNER; LARCKER, 2001) deixa de ser o ponto central de toda a questão e se transforma em ator secundário perante os comentários apresentados; contudo, os dois autores tentaram proporcionar uma réplica à análise crítica oferecida por Zimmerman (2001), concentrando suas discussões sobre três pontos principais: (i) pesquisa orientada para a prática. Consideram que, diferentemente das ciências naturais, a Contabilidade se constitui em um tipo de área de pesquisa aplicada que deve proporcionar novas propostas para prática. Dessa maneira, a pesquisa aplicada deve tratar os problemas da Contabilidade Gerencial destacando os fatores relevantes em termos de economia, comportamento organizacional e ambiente que influenciam a adoção, o uso e os produtos da Contabilidade Gerencial. Esses dados, combinados com teorias matemáticas e não matemáticas, proporcionam base para o desenvolvimento e aperfeiçoamento de modelos e hipóteses para o subsequente teste. Consideram difícil pensar em pesquisa em uma disciplina aplicada, como é o caso da Contabilidade Gerencial, sem o benefício do exame de práticas reais. Citam Zimmerman (1997, p. 13) que disse: “[...] não é porque um dado sistema sobrevive que significa que seja ótimo. Um sistema melhor pode existir e não ter sido descoberto." Consideram que o foco na prática não deve ser algo que prescinda da teoria. Apesar da crítica de Zimmerman sobre as práticas serem mais orientadas para a descrição do que o desenvolvimento de teorias, esse comentário é inconsistente com a massa de estudos publicados nos periódicos acadêmicos, já que os pesquisadores de Contabilidade Gerencial estão testando uma variedade significativa de teorias econômicas e não econômicas. Citam como exemplo o trabalho de Lambert (2001), argumentando que muitos tópicos cobertos pelo modelo são motivados pela adoção das novas práticas de Contabilidade Gerencial, tais como Balanced Scorecard e mensuração de lucro residual. Além disso, muitas práticas apresentadas por consultores, tais como $\mathrm{ABC}$, just-in-time, qualidade total, continuam a ser utilizadas por um grande número de organizações. Nesse sentido, é relevante para os pesquisadores da Contabilidade Gerencial entender por que as organizações estão adotando essas práticas de consultoria, se elas apresentam algum benefício econômico e suas condições de realçar ou retardar sua utilidade. Somente estudando as práticas reais é possível trazer tais respostas e um estudo de campo não é nem simples nem mal definido como alguns consideram; (ii) testes de performance. Muitas teorias (econômicas e não econômicas) tentam identificar práticas organizacionais ótimas sob um certo grupo de condições. Existe uma grande dificuldade de relacionar a performance econômica com a utilização de práticas contábeis gerenciais, sendo inclusive os problemas de endogeneidade estatística um dos motivos para a recusa desses trabalhos nos periódicos. O problema é que as premissas econômicas do modelo em que os tomadores de decisão são racionais e buscam maximizar o valor de suas escolhas não são consistentes. Citam inclusive que isso é inconsistente com a economia evolucionária prevista no livro texto de Zimmerman (1997) e muitas teorias comportamentais e derivadas de trabalhos de campo. O modelo resultante, implicitamente ou explicitamente, implica que essas organizações que adotam 
o modelo ótimo terão um desempenho melhor do que aqueles que não adotam. Para fazer isso, o pesquisador teria de analisar as diferenças de desempenho entre aqueles que adotaram e aqueles que não adotaram um artefato contábil específico. Se todas as empresas tivessem otimizado suas práticas de Contabilidade Gerencial não haveria nenhuma associação entre as práticas e o desempenho; (iii) lições da literatura de finanças. Os modelos econômicos são baseados em um grupo de premissas precisas sobre maximização da utilidade, comportamento racional dos indivíduos, estrutura de informações, formação de preços de mercado, e outros atributos importantes referentes a conjunto de decisão de interesse do pesquisador. Esses modelos proporcionam uma visão integrada dos problemas de pesquisa porque eles abstraem muitos elementos que afetam o real processo decisório. Ignorar teorias alterna- tivas limita o entendimento dos fenômenos organizacionais e gera danos para a profissão contábil-acadêmica. Existem muitas questões que exigem explicações comportamentais como, por exemplo: "[...] economics is the premier science, this science seems incapable of providing answers to many important and fascinating contemporary finance puzzles and anomalies [...]" (ITTNER; LARCKER, 2002, p. 791). Os próprios pesquisadores em finanças têm utilizado novas abordagens, principalmente psicológicas, dado que a economia não tem respondido satisfatoriamente a muitas questões. Por fim, concordam que falta para a Contabilidade Gerencial um conjunto integrado de teorias para a sua sustentação e defendem uma combinação de abordagens comportamentais com a econômica, para um entendimento mais completo do objeto de estudo da Contabilidade Gerencial.

\section{ARCABOUÇO TEÓRICO DA ANÁLISE DE ZIMMERMAN E ALGUMAS CONSIDERAÇÕES SOBRE A TEORIA POSITIVA}

A leitura das críticas de Zimmerman tem como pano de fundo a sua experiência e as suas crenças epistemológicas. Para analisá-lo, com um mínimo de respeito metodológico, é necessário entender a sua visão do que seria o positivismo em pesquisa contábil, que não necessariamente coincide com a visão de positivismo sobre o enfoque epistemológico (DEMO, 2000). Segundo Watts e Zimmerman (1990), a abordagem positiva da Contabilidade originou-se dos trabalhos de Ball e Brown (1968) e Beaver (1968), como uma tentativa de incorporar à metodologia empírica de finanças questões relativas ao relacionamento da Contabilidade com o mercado de capitais. Posteriormente, o trabalho de Watts e Zimmerman (1986) estabeleceu e consolidou importante arcabouço teórico para o estudo de questões relacionadas à Contabilidade Financeira e Auditoria. Eles estabeleceram fundamentos teóricos e futuras hipóteses a serem testadas.
Basicamente, a inspiração metodológica para a teoria positiva da Contabilidade é a teoria positiva da economia de Friedman (1966) vinculado à Escola de Economia de Chicago derivada da corrente neoclássica e gerando o novo classicismo (BRUE, 2005). Fülbier e Selhorn (2006) indicada com a teoria positiva da economia tem origens nos trabalhos de David Hume - "Tratado da Natureza Humana” (HUME, 2001) publicado pela primeira vez em 1739 - e Keynes The scope and method of political economy (KEYNES, 1917) publicado pela primeira vez em 1891 preocupados em fazer uma ciência "pura”. Também com inspiração no método hipotético-dedutivo de Popper (1997). A premissa básica era a necessidade de construir uma ciência "dura" em oposição à política econômica, valorativa e propositiva que era a dominante. O autor arguia que a função da economia era explicar e descrever (economia positiva) efetiva- 
mente como o mundo é e não como ele deve ser (política econômica). Assim, a economia positiva servia de base para a descrição e explicação dos fenômenos do mundo real com um modelo de cientificidade semelhante às ciências naturais.

A teoria positiva da Contabilidade apropriou-se de alguns desses rótulos. $\mathrm{Na}$ época de sua criação, na década de 60 , as pesquisas contábeis existentes eram de natureza precipuamente normativa. Os pesquisadores buscavam incorporar conceitos da economia para indicar qual seria o melhor procedimento contábil, a partir da concepção de um determinado autor. As discussões giravam em torno de estabelecer qual a melhor forma de avaliar o lucro, ativo e outros elementos do arcabouço contábil.

A abordagem positiva, em oposição à normativa, floresceu incorporando os conceitos da economia para o entendimento do impacto real da Contabilidade nos seus usuários, particularmente no mercado de capitais. Nesse sentido, semelhante à economia, a Contabilidade deveria explicar "por que acontece o fenômeno contábil?” e prever “em que circunstâncias podem ocorrer o fenômeno?". Essa abordagem da Contabilidade tem uma influência dos trabalhos de Popper (1997) principalmente em relação ao método hipotético-dedutivo, mas também possui dissimilaridades (KABIR, 2007).

Uma questão relevante é que o termo "teoria positiva" foi estabelecido por Watts e Zimmerman (1990) como um mero rótulo para incorporar o conjunto de teorias baseadas na economia que visavam explicar o relacionamento entre informações contábeis e mercado de capitais. Assim, essa visão não abarca todo o espectro da expressão positiva no sentido epistemológico da expressão (DEMO, 2000), mesmo compartilhando algumas premissas com esta concepção, principalmente quanto à visão de mundo dos pesquisadores. Outras áreas, tais como o direito, também possuem a sua teoria positiva e sequer apresenta conotação empírica (KELSEN, 2006), tampouco se confunde com as abordagens da epistemologia. Adicionalmente, constata-se que existem abordagens que são utilizadas na Contabilidade como a teoria da contingência que possui uma raiz positivista sob o ponto de vista epistemológico, mas não pode ser contemplada na visão Zimmermaniana do termo. Os próprios autores (WATTS; ZIMMERMAN, 1990) no ensaio "Positive Accounting Theory: A Ten Year Perspective" de 1990, trataram de desmistificar o uso do rótulo:

"our use of the term "positive" differentiated our and other people's (positive) research from traditional normative theories by emphasizing the importance of prediction and explanation. It helped place normative theories and their role in a clearer perspective (...) The phrase "positive" created a trademark and like all trademarks it conveys information (....) In retrospect, the term "positive" generated more confusion than we anticipated (...) We merely intended to distinguish positive propositions from the extant normative propositions in the literature (...) While the term "positive" avoided debates over normative uses of the work, the term "positive" generated considerable debate over philosophical issues... Despite its problems, we prefer "positive accounting literature" to alternative terms that have arisen (....)".

Conclui-se que a abordagem positiva de Watts e Zimermman (1986) foi um rótulo criado pelo autor para indicar o estudo do fenômeno contábil a partir de uma abordagem de previsão e explicação (o que "é”) com a utilização de teorias econômicas neoclássicas.

Apesar de sua grande utilização, a teoria positiva da Contabilidade tem sido alvo de diversas críticas (TINKER et al., 1982; WHITLEY, 1988; WILLIAMS, 1989), por apresentar aspectos epistemológicos e metodológicos não totalmente aceitos por determinadas comunidades de pesquisadores da área. 
Nesse ponto, é fundamental reiterar que a proposta de teoria positiva da Contabilidade foi desenvolvida precipuamente para a área de Contabilidade Financeira e auditoria. Para uma abordagem "positiva" na Contabilidade Gerencial, semelhante à estabelecida por Watts e Zimmerman, seria necessário o estabelecimento de teorias e hipóteses baseadas no relacionamento entre questões econômicas e Contabilidade Gerencial. Entretanto, apesar de não terem um arcabouço definido como teoria positiva em Contabilidade Gerencial, têm-se verificado trabalhos com uma abordagem econômica, mas não como um arcabouço teórico tal como o estabelecido em Watts e Zimmerman (1986).

Uma das características da pesquisa em Contabilidade Gerencial na abordagem econômica é o seu foco na maximização da riqueza dos acionistas e uma busca da eficiência da firma, com uma abordagem epistemológica de natureza positivista (BROMWI$\mathrm{CH}, 2007)$. Seus principais temas referem-se a orçamento de capital e lucro residual, medidas de desempenho, inclusive medidas nãofinanceiras e baseadas em plano de incentivos em ações, preços de transferência e alocação de custos (BROMWICH, 2007). Das diversas áreas da economia, a que tem sido mais proeminente é a teoria da agência (LAMBERT, 2001, 2007).

Nesse ponto, vale ressaltar a importância da economia na histórica criação de artefatos pelos práticos em Contabilidade Gerencial, tais como orçamento, custeio direto, Contabilidade por responsabilidade e preços de transferência (BOYNS; EDWARDS, 2007;
FLEISCHMAN, 2007; JOHNSON; KAPLAN, 1993). O desenvolvimento desses artefatos seguiu as premissas da economia neoclássica (racionalidade ilimitada, maximização de utilidade dos agentes e ausência de restrição cognitiva no processamento de informações pelos agentes) mas os problemas relacionados à sua aplicação podem demandar outros paradigmas.

No campo de pesquisa, a abordagem econômica tem tido uma participação relevante para o estudo dos problemas do campo (MENSAH et al., 2004), mas conforme as revisões dos trabalhos efetuados, essa abordagem não tem sido utilizada para analisar todos os tipos de problemas da Contabilidade Gerencial como deseja Zimmerman (2001). Esse fato demonstra a dificuldade da área em obter ganhos de escala utilizando-se de um único paradigma, tal como ocorre no conceito de eficiência da ciência normal em Kuhn (1970).

Em síntese, além de perceber o mundo da pesquisa positiva sendo entendido de diferentes perspectivas, a própria dicotomia normativista versus positivista é um reducionismo muito grande do potencial de compreensão da Contabilidade e sua relação com pessoas, organizações e sociedade. Como exemplo de alternativas, Baxter e Chua (2005) apresentaram abordagens naturalistas, latourianas, não-racionais, críticas, foucaultianas, estruturalistas, comportamentais etc. A consequência da aceitação dessas abordagens pode ser o aumento da abrangência do poder da Contabilidade em resolver problemas relevantes da sociedade.

\section{ELEMENTOS RELEVANTES NO DEBATE}

A sequência de artigos é de grande riqueza de temas e numa linguagem pouco vista no ambiente acadêmico. Trata-se de "lavar a roupa suja na frente das visitas". Para o presente ensaio foram escolhidos alguns pontos, relevantes, na opinião dos autores deste tra- balho, para o crescimento do conhecimento acadêmico em Contabilidade. Antes de particularizar, é importante entender que debates acadêmicos deveriam ser algo muito natural na vida dos pesquisadores; contudo, além de não serem, são entendidos como verdadeiras 
crises no lugar de serem formas de se expressar e divergir de maneira metodologicamente estruturada.

\subsection{Tipos de questões de pesquisa predominantes na pesquisa de Contabilidade Gerencial}

Esse é o ponto relevante no desenvolvimento do conhecimento em Contabilidade Gerencial. Na verdade serve de base para toda a discussão apresentada. A colocação de Zimmerman do privilégio, na verdade praticamente exclusividade, dos temas relacionados ao paradigma econômico é inaceitável do ponto de vista de pesquisa. Se os pesquisadores ignorarem as demandas legítimas das organizações em termos de resolver problemas, a sua dissociação com a realidade faria da pesquisa algo inútil. Dessa maneira, ao propor resolver as questões que incomodam o mundo das empresas, não é possível ignorar a exigência de que os pesquisadores estejam preparados para buscar outros paradigmas, além do econômico. Quando Zimmerman (2001) questiona a grande ênfase da Contabilidade Gerencial no processo decisório e não no controle, isso mostra o seu distanciamento já que a base do gerenciamento das organizações está no planejamento e, consequentemente, no processo decisório.

As especificidades da Contabilidade Gerencial no que tange à falta de padronização e regulação de seus dados, multiplicidade de demandas dos diversos usuários internos, bem como de seus diferentes problemas e instrumentos, têm tornado a disciplina mais aberta para diferentes abordagens epistemológicas. Uma questão que pode definir a qualidade da estrutura da pesquisa é a definição explícita dessa abordagem pelo autor do trabalho. Uma definição precisa dessas questões tem sérios impactos no que tange a aspectos metodológicos da pesquisa como, por exemplo, a teoria que vai ser utilizada, bem como aspectos da estrutura de disseminação científica da área de Contabilidade Gerencial como, por exemplo, o veículo de divulgação que pode aceitar o trabalho.

Outro aspecto relevante, e que decorre das especificidades, é o que Zimmerman (2001) chama de "mantra" sempre citado como dificuldade pelos pesquisadores em Contabilidade Gerencial: a dificuldade em obter informações. Isso é evidenciado no momento em que, por exemplo, em função da questão da pesquisa a ser tratada, um survey é requerido. Naturalmente, se a questão é relevante e o pesquisador deseja tratá-la, o empirismo vai demandar pesquisas muitas vezes específicas, o que representa custo maior do que para aquele pesquisador que pode tratar a questão de pesquisa a partir de dados disponíveis. Isso é uma realidade, mas não deveria servir de desculpa para retardar o crescimento da área.

A discussão decorre da presença do monoparadigma, pois muitas questões de pesquisa não podem ser respondidas apenas pela abordagem econômica. Na discussão proposta por Lukka e Mouritsen (2002), referem-se ao "COMO". O tratamento dessas perguntas pode eventualmente ter apoio de construtos de teorias organizacionais, como teoria institucional, teoria da contingência, ciclo de vida, teoria da configuração, dentre outros, que fogem ao monoparadigma e seu pacote metodológico.

\subsection{Coerência e consistência metodológica dos estudos}

Outra questão relevante refere-se às implicações relativas à coerência metodológica da pesquisa definida a partir do paradigma adotado. Tanto o paradigma positivista quanto o fenomenológico utilizam-se de instrumentos como entrevistas, questionários, bem como análise de dados quantitativos e qualitativos, entretanto o que distingue as duas versões é essencialmente a forma de enxergar a realidade (AHRENS; CHAPMAN, 2006). No paradigma positivista, o sujeito se encontra distante do objeto pesquisado. A busca é por 
relações causais entre fenômenos em uma linguagem pessoal e fechada, com pesquisas geralmente guiadas por hipóteses. Sua finalidade é explicar e prever os fenômenos da Contabilidade Gerencial.

Não se advoga o desprezo pelo paradigma positivista. Alguns exemplos de pesquisa com esse paradigma incluem Henri (2006) que investigou a relação entre a utilização de sistemas de controle gerencial e a criação e destruição de capacidades organizacionais intangíveis; o trabalho de Naranjo-Gil e Hartmann (2007) que analisaram como o grau de heterogeneidade da cúpula gerencial afeta as mudanças estratégicas por meio do desenho e uso dos sistemas de controle gerencial pelos dirigentes; Bryant, Jones e Widener (2004) que analisaram dados de 5 anos de 125 empresas para verificar como múltiplas medidas de performance (BSC) indicavam a criação de valor das firmas; e Chong e Eggleton (2007) que estudaram os efeitos da informação assimétrica e compromisso organizacional na relação entre a extensão e confiança no sistema de incentivos para executivos da firma.

$\mathrm{Na}$ pesquisa fenomenológica em Contabilidade Gerencial, o sujeito se encontra próximo do objeto investigado, a realidade emerge do trabalho de campo, a teoria pode ser concebida a partir da prática da pesquisa (por exemplo, utilizando "grounded-theory") e não há preocupação em relação à existência de hipóteses.

Diversos trabalhos têm sido elaborados nessa abordagem. O trabalho clássico de Miller e O'Leary (1987) mostra, mediante um estudo de caso, como sistemas de custos e orçamentos são utilizados para controlar indivíduos em busca de eficiência. Nesse artigo, os autores criticam o discurso da racionalidade utilizando como bases teorias da psicologia e do poder de Focault. Destaquem-se, também, Briers e Chua (2001) que explanaram sobre o papel da rede de atores (teoria da rede em Latour) e crenças na mudança do sistema de Contabilidade Gerencial em uma empresa e o trabalho de Thrane (2007) que relata mudanças no sistema de Contabilidade Gerencial em uma rede de organizações complexas.

Nesse ponto do texto, cabe efetuar uma discussão da importância de olhar a pesquisa em uma visão integrativa desses paradigmas. Uma questão é que essas duas abordagens podem ser analisadas visando a um entendimento mais amplo da totalidade do objeto investigado, além disto, autores têm se insurgido contra a rigidez da dicotomia subjetividade-objetividade (por exemplo, Peci, 2004), tais como propugnado por Berger e Luckmann (1996). Os autores deste trabalho consideram que a diversidade de visões pode ser uma realidade no intuito de proporcionar um entendimento mais profícuo do campo. Isto pode ocorrer, inclusive, no mesmo trabalho. O artigo de Moores e Yuen (2001), que utilizou uma abordagem configuracional para padrões dos sistemas de controle gerencial ao longo do ciclo de vida de empresas, é um exemplo dessa postura epistemológica. Inicialmente os autores fizeram uma survey com teste de hipóteses e modelos estatísticos. Nesse caso, procuraram entender "SE" existia um padrão (positivista). Posteriormente, estudos multicasos (de natureza subjetiva) foram realizados para entender "COMO" (fenomenológico) ocorriam essas mudanças em algumas empresas representativas da própria amostra.

Adicionalmente, autores têm advogado sobre a necessidade de um critério de cientificidade próprio para as ciências humanas, dada a sua diferença de objeto e escopo em relação às ciências naturais (DOMINGUES, 2004).

\subsection{Visões preditiva e descritiva: estágios das áreas de pesquisa}

Todo o desenvolvimento da ciência pressupõe que o estágio preditivo seja alcançado; entretanto, sem uma base conceitual robusta, as respostas preditivas não são possíveis e os trabalhos descritivos podem ser uma etapa 
que antecede o desenvolvimento da pesquisa com fins preditivos ou ter uma visão de convívio entre descrever e predizer. As organizações se envolvem em questões legítimas dentro das suas atividades e a abordagem de Lukka e Mouritsen (2002), privilegiando o COMO (como funciona, eminentemente descritivo), no lugar do SE (se a Contabilidade Gerencial impacta o valor da empresa, o que permite prever o comportamento futuro), permite o seu crescimento. O que Zimmerman questiona é que muito tempo está decorrendo para que respostas proporcionem construção de teorias que aperfeiçoem a previsão. Nesse sentido, cobrar como monoparadigma que todos os problemas relevantes da Contabilidade sejam tratados à luz da perspectiva de proporcionarem respostas para a previsão, além de ignorar que existam outras demandas das empresas, não resolve esse problema.

\subsection{Escassez de veículos reconhecidos para publicação}

Essa é uma realidade da Contabilidade Gerencial, internacional e nacional. Em primeiro lugar, o conceito de mainstream não é algo indiscutível na área nem mesmo quem o comporia. Embora Zimmerman argumente que existam publicações de autores de Contabilidade Gerencial nos periódicos norte-americanos, a sua participação é ainda pequena. Menor ainda é participação de autores não norte-americanos. A necessidade de tornar claro qual o paradigma utilizado pelo pesquisador apresenta diversos reflexos no processo de pesquisa. Esses reflexos são de natureza relativa à estrutura da divulgação científica e política presente no campo, incluindo estrutura de poder, com implicações relativas à coerência metodológica da pesquisa.

A natureza da divulgação científica e política compreendem o modelo de validade de conhecimento que foi estabelecido na academia contábil. Dentre os principais periódicos de Contabilidade mundial, de acordo com o indicador de impacto - ISI, tais como Review of Accounting Studies, JAE, The Accounting Review e Accounting, Organization and Society, AOS, apenas esse último normalmente aceita trabalhos com diversificação paradigmática, como a epistemologia fenomenológica, por exemplo. Os demais aceitam pesquisas quase que exclusivamente baseadas na lógica positivista. Esse engessamento e conservadorismo da área têm sido discutidos por diversos autores como uma das causas da pouca inovação na pesquisa contábil (HOPWOOD, 2007; DYE, 2001). Essa situação pode ser refletida a partir das constatações de Bourdieu (1992) que assevera sobre os mecanismos de reprodução social que visam à legitimação daquilo que é considerado como "o correto", nesse caso na comunidade científica, a partir da reiteração de discursos, ocorrendo, assim, o chamado poder simbólico na estrutura da comunidade científica de Contabilidade.

\section{COMENTÁRIOS FINAIS E RECOMENDAÇÕES}

Neste trabalho, não se pretendeu questionar a importância e a utilidade da abordagem positivista de Zimmerman, mas, sim, demonstrar, a partir da análise dos artigos aqui discutidos, que o monoparadigma é altamente limitador e nocivo ao crescimento da área, além de trazer consequências políticas e de poder no mundo da pesquisa. O problema central do monoparadigma está no fato de que ao optar por ele, provavelmente, algumas questões de pesquisa deixarão de ser tratadas pelos pesquisadores. De qualquer forma, a agressiva abordagem de Zimmerman foi muito útil para a comunidade da Contabilidade Gerencial e alguns pontos de reflexão e recomendações podem ser indicados:

Questionamento do desenvolvimento da Contabilidade Gerencial. Isso pode ser per- 
cebido pela geração do conhecimento sob o "mantra" do monoparadigma, tanto quantitativamente como qualitativamente. Esse questionamento proporciona reflexão que pode ir tanto para a contestação sobre a existência de crescimento do conhecimento como pela especificidade, ou seja, que o crescimento tem de ser visto de outras maneiras além do positivismo "Zimmermaniano" e, ainda mais, no mainstream norte-americano.

Especificidades da Contabilidade Gerencial. Em pesquisa TUDO deve ser subordinado a uma questão relevante e com desenvolvimento factível. A plataforma metodológica, os métodos devem ser subordinados à questão. Nessa linha de raciocínio, não se recomenda que os pesquisadores abandonem os conhecimentos existentes e repudiem SEUS mainstreams, a sua corrente principal, mas que estejam abertos ao entendimento da alternativa de construto que permita resolver a questão de pesquisa de maneira satisfatória para o momento vivido.

Muito do que se faz em Contabilidade Gerencial ainda requer melhoria de qualidade metodológica. Dizer apenas que as especificidades existem e que "vale tudo" na pesquisa não vai atrair um olhar empático da comunidade. Todos os autores aqui mencionados reconhecem que o rigor metodológico deve ser perseguido. O que fica em aberto é, a partir de um direcionamento de questão de pesquisa, buscar a metodologia adequada e torná-la útil para o trabalho. Uma vez feito isso, o acúmulo de conhecimento pode ser verificado, aproximando-se da realidade prática do monoparadigma. Provavelmente isso tem um efeito relevante no comentário pertinente que Zimmerman fez sobre o fracasso do avanço do conhecimento em Contabilidade Gerencial. Embora entendendo as especificidades de cada pesquisador e seu interesse, muitos trabalhos, caso fossem desenvolvidos de maneira consistente com os antecedentes, teriam contribuído para o crescimento do conhecimento.

Interesse dos periódicos. Pluralismo é uma intenção que só se percebe como verdadeira quando demonstrado de forma prática, ou seja, ao gerar e desejar publicar um artigo, o autor deve ter a consciência de que está entrando num mundo de crenças e poder. Nesse cenário, uma análise pragmática indica que, para que o pesquisador tenha seus achados divulgados em veículos de impacto na comunidade acadêmica, suas crenças devem ter afinidade com aquelas professadas pelo editor. A dimensão poder está presente nessa atividade e os pesquisadores deveriam refletir se desejam preservar suas convicções ou ter seus trabalhos aceitos rapidamente.

Particularmente nesse momento vivido, a Contabilidade Gerencial precisa de uma personalidade, "uma cara", seja ela qual for. O que se espera dessa área de conhecimento é que suas opções sejam conscientes e não simplesmente resultantes de uma série de pressões. Ao traduzir essa questão para a dimensão individual do pesquisador, não se pretende que um dado estudioso só se proponha a estudar as questões que estão "na moda", mas sim aquilo que ele considere relevante para si e o seu ambiente de atuação, de maneira constante e coerente em um horizonte de longo prazo.

\section{Referências}

AHRENS, T.; CHAPMAN, C. Doing qualitative weld research in management accounting: Positioning data to contribute to theory. Accounting, Organizations and Society, v. 31, p. 819-841, 2006.

ANUAL DA ASSOCIAÇÃO NACIONAL DE PÓS-
GRADUAÇÃO E PESQUISA EM ADMINISTRAÇÃO, 2007, Rio de Janeiro: ENANPAD 2007. v. 1. p. 1. BAXTER, J; CHUA, W. F. Reframing management accounting practice: a diversity of perspectives. In: BHIMANI, A. Contemporaty issues in management accounting. Oxford: Oxford University Press, 2006. 
BERGER, P. L.; LUCKMANN, T. A. Construção social da realidade. Petrópolis: Vozes, 1996.

BOURDIEU, P. O poder simbólico. Rio de Janeiro:

Bertrand Brasil, 1992.

BOYNS, T.; EDWARDS, J. R. The development of cost and management accounting in Britain. In: CHAPMAN, C. S.; HOPWOOD, A. G.; SHIELDS, M. D. Handbook of management accounting research, v. 1. Amsterdam: Elsevier, 2007.

BRIERS, M.; CHUA, W. F. The role of actor-networks and boundary objects in management accounting change: a field study of implementation of active-based costing. Management Accounting Research, v. 26, p. 237269, 2001.

BROMWICH, M. Economics in management accounting. In: CHAPMAN, C. S.; HOPWOOD, A. G.; SHIELDS, M. D. Handbook of Management Accounting Research, v. 1. Amsterdam: Elsevier, 2007.

BRUE, S. L. História do pensamento econômico. São Paulo: Pioneira Thomson Learning, 2005.

BRYANT, L.; JONES, D. A.; WIDENER, S. K. Managing value creation within the firm: an examination of multiple performance measures. Journal of Management Accounting Research, v. 16, p. 107-131, 2004.

BURREL, G.; MORGAN, G. Sociological paradigms and organizational analysis: elements of the sociology of corporate life. London: Heinemann, 1979.

CHONG, V. K.; EGGLETON, I. R. C. The impact of reliance on incentive-based compensation schemes, information asymmetry and organizational commitment on managerial performance. Management Accounting Research, v. 18, p. 312-342, 2007.

COLLIS, J.; HUSSEY, R. Pesquisa em administração: um guia prático para alunos de graduação e pós-graduação. Porto Alegre: Bookman, 2005.

COPELAND, T.; KOLLER, T.; MURRIN, J. Valuation: measuring and managing the value of companies. New York: Wiley, 1996.

DEMO, P. Metodologia do conhecimento científico. São Paulo: Atlas, 2000.

DOMINGUES, I. Epistemologia das ciências humanas - tomo I: positivismo e hermenêutica - Durkheim e Weber. São Paulo: Edições Loyola, 2004.

DYE, R. A. An evaluation of "essays" on disclosure and the disclosure literature in accountings. Journal of Accounting and Economics, v. 32, p. 181-235, 2001. FLEISCHMAN, R. The history of management accounting ideas in the U.S. In: CHAPMAN, C. S.; HOPWOOD, A. G.; SHIELDS, M. D. Handbook of Management Accounting Research, v. 1. Amsterdam: Elsevier, 2007.

FRIEDMAN, M. Essays in positive economics. London: University of Chicago Press, 1966.

FULBIER, R, U; THORSTEN, S. Methodological. approaches to accounting research - Evidence from EAA annual congress. Disponível em: <http://ssrn.com/ abstract=985119 $>$. Acesso em: 2 jul. 2008.

HENRI, Jean-F. Management control systems and strategy: a resource-based perspective. Accounting, Organizations and Society, v. 31, p. 529-558, 2006. HOPWOOD, A. G. Whiter accounting research? The
Accounting Review, v. 82, p. 1365-1374, 2007.

If only there were simple solutions, but there aren't: some reflections on Zimmerman's critique of empirical management accounting research. The European Accounting Research, v. 11, n. 4, p. 777-785, 2002.

; SHIELDS, M. D. Handbook of management accounting research, v. 1. Amsterdam: Elsevier, 2007. HUME, D. Tratado da Natureza Humana. São Paulo: Editora Unesp, 2001.

ITTNER, C. D.; LARCKER, D. F. Assessing empirical research in managerial accounting: a value-based management perspective. Journal of Accounting and Economics, v. 32, p. 349-410, 2001. . Empirical managerial accounting research: are we just describing management consulting practice? The European Accounting Research, v. 11, n. 4, p. 787-794, 2002.

JOHNSON, H. T.; KAPLAN, R. S. Contabilidade gerencial: a restauração da relevância da Contabilidade nas empresas. Rio de Janeiro: Campus, 1993. KABIR, Md, H. Positive accounting theory and science: a comparison. Disponível em: <http://ssrn.com/ abstract=1027382 $>$. Acesso em: 02 jul. 2008,

KAPLAN, R. S.; THOMAS, J. H. Contabilidade Gerencial. Rio de Janeiro: Campus, 1993.

KELSEN, H. Teoria pura do direito: introdução à problemática científica do direito. São Paulo: Revista dos Tribunais, 2006.

KEYNES, J. N. The scope and method of political economy. London: Macmillan, 1917.

KUHN, T. A estrutura das revoluções científicas. São Paulo: Perspectiva, 1970.

LAMBERT, R. A. Agency theory and management accounting. In: CHAPMAN, C. S.; HOPWOOD, A. G.; SHIELDS, M. D. Handbook of Management Accounting Research, v. 1. Amsterdam: Elsevier, 2007.

. Contracting theory and accounting. Journal of Accounting and Economics, v. 32, p. 3-87, 2001. LUFT, J.; SHIELD, M. D. Mapping management accounting: graphics and guidelines for theoryconsistent empirical research? Accounting, Organizations and Society, v. 28, p. 169-249, 2003.

Zimmerman's contentious conjectures: describing the present and prescribing the future of empirical management accounting research.

The European Accounting Review, v. 11, n. 4, p. 795-805, 2002.

LUKKA, K.; MOURITSEN, J. Homogeneity or heterogeneity of research in management accounting? The European Accounting Review, v.11, n. 4, p. 805-811, 2002.

MENSAH, Y. M.; NEN-CHEN, R. H.; WU, D. Does managerial accounting research contribute to related disciplines? An examination using citation analysis. Journal of Management Accounting Research, v. 16, p. 163-181, 2004.

MERCHANT, K. A.; VAN Der STEDE, W. A. Field-based research in accounting: accomplishments and prospects. Behavioral Research in Accounting, v. 18, p. 117-134, 2006. 
MILLER, P.; O'LEARY, T. Accounting and the construction of the governable person. Accounting, Organizations and Society, v. 12, p. 235-265, 1987. MOORES, K.; YUEN, S. Management accounting systems and organizational configurations: a life-cycle perspective. Accounting, Organizations and Society, v. 26, p. 351-389, 2001.

NARANJO-GIL, D.; HARTMANN, F. Management accounting systems, top manangement team heterogeneity and strategic change. Accounting, Organizations and Society, v. 32, p. 735-756, 2007. PECI, A. Além da dicotomia objetividade-subjetividade. In: VIEIRA, M. M. F.; ZOUIAN, D. M. Pesquisa Qualitativa em Administração. Rio de Janeiro: FGV, 2004. POPPER, K. A lógica da pesquisa científica. São Paulo: Pensamento-Cultrix, 1997.

SALVADOR, A. D. Métodos e técnicas de pesquisa bibliográfica. Porto Alegre: Sulina Editora, 1980. SANTOS, A. R. Metodologia científica: a construção do conhecimento. Rio de Janeiro: D\&P Editora, 1999. THRANE, S. The complexity of management accounting change: bifurcation and oscillation in schizophrenic inter-organizational systems. Management Accounting Change, v. 18, p. 248-272, 2007.
TINKER, A. M.; MERINO, B. D.; NEIMARK, M. D. The normative origins of positive theories: ideology and accounting thought. Accounting, Organizations and Society, v. 7, n. 2, p. 167-200, 1982.

VASCONCELLOS, M. J. E. Pensamento sistêmico: o novo paradigma da ciência. Campinas: Papirus Editora, 2005. WATTS, R. L.; ZIMMERMAN, J. L. Positive accounting theory: a ten year perspective. The Accounting Review, v. 65, p. 131-156, 1990.

Prentice-Hall, 1986

Positive accounting theory. New Jersey:

WHITLEY, R. D. The possibility and utility of positive accounting theory. Accounting, Organizations and Society, v. 13, n. 6, p. 631-645, 1988.

WILLIAMS, P. F. The logic of positive accounting research. Accounting, Organizations and Society, v. 14, n. 6, p. 455-468, 1989.

ZIMMERMAN, J. L. Accounting for Decision making and control. Chicago, IL: Irwin, 1997.

Conjectures regarding empirical managerial accounting research. Journal of Accounting and Economics, v. 32, p. 411-427, 2001. 